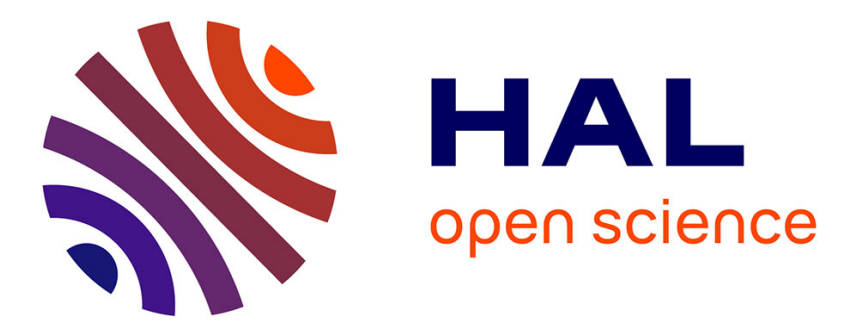

\title{
The influence of tocolytic drugs on cardiac function, large arteries, and resistance vessels
}

\author{
Isabelle G. Fabry, Peter Paepe, Jan G. Kips, Luc M. Bortel
}

\section{To cite this version:}

Isabelle G. Fabry, Peter Paepe, Jan G. Kips, Luc M. Bortel. The influence of tocolytic drugs on cardiac function, large arteries, and resistance vessels. European Journal of Clinical Pharmacology, 2011, 67 (6), pp.573-580. 10.1007/s00228-011-1040-5 . hal-00687813

\section{HAL Id: hal-00687813 https://hal.science/hal-00687813}

Submitted on 15 Apr 2012

HAL is a multi-disciplinary open access archive for the deposit and dissemination of scientific research documents, whether they are published or not. The documents may come from teaching and research institutions in France or abroad, or from public or private research centers.
L'archive ouverte pluridisciplinaire HAL, est destinée au dépôt et à la diffusion de documents scientifiques de niveau recherche, publiés ou non, émanant des établissements d'enseignement et de recherche français ou étrangers, des laboratoires publics ou privés. 


\title{
The influence of tocolytic drugs on cardiac function, large arteries and resistance vessels
}

Short title: Cardiac and vascular effects of tocolytic drugs

\author{
Isabelle G. Fabry ${ }^{1}$, Peter De Paepe ${ }^{1,2}$, Jan G. Kips ${ }^{1}$, Luc M. Van Bortel ${ }^{1}$
}

Word Counts: Whole Manuscript 3120; Abstract 250

Number: Tables 3, Figures 0

Original Manuscript with Agreement of all the Authors with the Content of the Work

No Conflicts of Interests

\author{
Correspondence to: \\ Isabelle Fabry, MD, \\ Heymans Institute of Pharmacology, \\ Department of Clinical Pharmacology, \\ Ghent University Hospital, \\ De Pintelaan 185, \\ B-9000 Gent, \\ Belgium. \\ Telephone: $\quad+32-9-332-0040$ (office) \\ +32-472-47-2816 (mobile) \\ Facsimile: $\quad+32-9-332-8800$ (office) \\ Email: isabelle.fabry@ugent.be
}


1 Heymans Institute of Pharmacology, Department of Clinical Pharmacology, Ghent University, Ghent, Belgium;

2 Emergency Department, Ghent University Hospital, Ghent, Belgium.

Keywords: atosiban, ritodrine, cardiovascular function.

Correspondence and requests for reprints to Isabelle Fabry. 
What this study adds

What is already known about the subject?

1. Mainly reports of ritodrine on the blood pressure and cardiovascular side effects are known;

2. Apart from blood pressure, no cardiovascular effects have been studied during atosibaninfusion;

3. Therefore, there is a need for in depth research on the effects of the two commonly used tocolytic drugs on the cardiovascular system to better understand their pharmacodynamic effects.

What this study adds:

Comparison of the effects of ritodrine and atosiban on macrocirculation (arterial stiffness and compliance), microcirculation (peripheral resistance) and cardiac function. 


\section{Abstract}

Background: Beta-2 adrenoceptor agonistic drugs like ritodrine have been the reference tocolytic drugs but are associated with cardiovascular side-effects. Atosiban, a newer drug, is a competitive antagonist of oxytocin and has been claimed to have less cardiovascular side effects. Until now, there is mainly a subjective reporting of adverse reactions and little objective, cardiovascular data.

Aims: Evaluation of the acute effects of therapeutic doses of ritodrine and atosiban compared to placebo on cardiac function, large artery properties, blood pressure and resistance vessels.

Methods: A double-blind, randomized trial was carried out in twenty non-pregnant female volunteers. Hemodynamic measurements were done under standardized conditions during kinetic steady state. Cardiac output was measured with echocardiography, large artery properties with an echo-tracking device. The effect on the microcirculation was estimated using the total peripheral resistance index (TPRI).

Results: Atosiban did not differ from placebo. With ritodrine, cardiac function increased with $79 \%$ compared to placebo due to a rise in heart rate (91\%). TPRI decreased with $48 \%$. Ritodrine increased the distensibility of the common carotid artery with $62 \%$ and the compliance with $83 \%$, independent from blood pressure. Compliance of the common femoral artery increased independently of pressure with $33 \%$ and the distensibility with 59\%. Aortic pulse wave velocity was not influenced by either medication.

Conclusions: The present study shows potential beneficial vascular effects of ritodrine. which are counterbalanced by the cardiac effects. Atosiban has no clinically relevant cardiovascular effects and may be a good alternative for ritodrine in pregnant women at risk for cardiovascular complications. 


\section{List of Abbreviations (in order of appearance)}

ICH: International Conference on Harmonisation

$\mu \mathrm{g}$ : microgram

min: minute

ml: milliliter

mmHg: millimeter Mercury

SBP: systolic blood pressure

DBP diastolic blood pressure

MAP: mean arterial pressure

HR: heart rate

CO: cardiac output

D: diameter

MHz: Mega Hertz

SV: stroke volume

CSA: cross-sectional area

Ao: aorta

FVI: flow velocity index

BSA: body surface area

CI: cardiac index

SI: stroke index 
TPRI: total peripheral resistance index

PWV: pulse wave velocity

CCA: common carotid artery

CFA: common femoral artery

SSN: supra-sternal notch

CC: cross-sectional compliance

DC: distensibility coefficient

$\Delta \mathrm{A}$ : systolic-diastolic change in arterial cross-section

$\Delta \mathrm{P}$ : local change in pulse pressure

PP: pulse pressure

$\Delta_{\mathrm{S}}:$ arterial diameter at end-systole

$\Delta_{\mathrm{D}}$ : arterial diameter at end-diastole

$\mathrm{A}_{\mathrm{D}}$ : arterial cross-section at end-diastole

PWF: pressure waveforms

$\mathrm{DC}_{\mathrm{ISO}}$ : isobaric distensibility coefficient

$\mathrm{CC}_{\mathrm{ISo}}$ : isobaric cross-sectional compliance

RAAS: Renin-Angiotensin-Aldosteron System 


\section{Introduction}

Preterm labor is the most frequently reported cause of perinatal morbidity and mortality in the Western world.[1] Tocolytic medication can postpone delivery.[2]

Beta-2 adrenoceptor agonistic drugs have been the reference tocolytic drugs in most countries.[1;3] Their efficacy in prolonging pregnancy compared to placebo is proven although no benefit in neonatal morbidity or mortality has been demonstrated. Beta-mimetics are not highly selective and have many contraindications. Side-effects are frequent due to beta-1 and -2 adrenoceptor agonistic cardiovascular effects. Even serious complications such as pulmonary oedema and maternal death, though rare, have been reported.[4]

Oxytocin receptor blockers are a new class of tocolytic drugs. The oxytocin antagonist atosiban has less side effects than beta-agonists.[5] However, it is no more effective than ritodrine and the benefit of safety has to be balanced against that of cost.[6;7] A study of Ferriols et al. revealed that the costeffectiveness obtained with the protocol including ritodrine as first-choice drug was three times less than when atosiban was used. In pregnant women where the likelihood of developing acute pulmonary oedema is high, or when cardiovascular risk is high (e.g. preeclampsia, cardiomyopathies, cardiovascular syndromes), atosiban may be an appropriate alternative option.[8] Although large studies using atosiban have been performed[4;9], there is mainly a subjective reporting of adverse reactions during infusion and objective data with regard to cardiovascular effects are scarce.

To the best of our knowledge, the hemodynamic effects on the heart and on the micro-and macrocirculation have not been studied before in a single study.[10] We evaluated the acute effects of therapeutic doses of ritodrine and atosiban on blood pressure, cardiac function, micro-circulation (total peripheral resistance) and macro-circulation (large artery stiffness) in healthy non-pregnant female volunteers. 


\section{Methods}

Subjects

Twenty healthy non-pregnant female volunteers, either non-smokers or controlled smokers $(\leq 10$ cigarettes per day) with adequate non-uteral contraception were recruited from the local population. All participants gave written informed consent upon screening, organised within two weeks before the planned first drug administration. They were apparently healthy (no cardiovascular disease arrhythmias included, obstructive lung disease, chronic kidney disease or diabetes mellitus). Breastfeeding women or women with a severe addiction were excluded.

Subjects were asked not to eat, smoke and drink caffeine-containing beverages for at least 3 hours before and during the measurements. They also had to refrain from drinking alcohol for at least 10 hours before measurements.[11]

Design

A double-blind, randomised trial was carried out at the Drug Research Unit Ghent of the Ghent University Hospital, Belgium. The study was approved by the Ethics Committee of Ghent University and conducted according to ICH Good Clinical Practice and the Declaration of Helsinki (last amended in 2008 in Seoul).

Twenty female volunteers were given atosiban (Tractocile ${ }^{\circledR}$, Ferring, Sweden) and placebo (Glucose $5 \%$ ) intravenously, in random order. Eight of them were randomly chosen to also get ritodrine (PrePar®, Eumedica, Belgium) in a single-blind way. The effects of drugs were compared after 95 minutes of infusion when kinetic steady state was reached for atosiban and ritodrine, being 15 minutes after starting the highest dose $(400 \mu \mathrm{g} / \mathrm{min})$ of ritodrine. Hemodynamic measurements were done by one investigator with the subjects in supine position and under standardized conditions (derived from the Task Force III, clinical applications for arterial stiffness[11]) including a temperature controlled $\operatorname{room}\left(22 \pm 1{ }^{\circ} \mathrm{C}\right)$. 


\section{Medication}

Each medication and placebo were infused for 120 minutes. Both atosiban and ritodrine were given with glucose $5 \%$ as vehiculum. Atosiban was given at a constant dose of $300 \mu \mathrm{g} / \mathrm{min}$ at a constant infusion rate of $0.4 \mathrm{ml} / \mathrm{min}$. Ritodrine was given in a dose escalation scheme starting with a dose of $100 \mu \mathrm{g} / \mathrm{min}$ gradually upgraded to a dose of $400 \mu \mathrm{g} / \mathrm{min}$. The infusion rate varied with each dosing step (from 0.23 to $0.53 \mathrm{ml} / \mathrm{min}$ ). Glucose $5 \%$ was given as placebo at a constant infusion rate of $0.4 \mathrm{ml} / \mathrm{min}$. Dosing was based on previous studies using atosiban or ritodrine[1;12-15] and on the manufacturers prescriptions. Each period, the subjects received a total volume of $48 \mathrm{ml}$.

Stopping criteria for dosing were: a heart rate increase above $75 \%$ of the age-based maximal heart rate or blood pressure changes from baseline of more than $30 \mathrm{mmHg}$ for systolic (SBP) and $15 \mathrm{mmHg}$ for diastolic blood pressure (DBP); a SBP above $180 \mathrm{mmHg}$ or less than $90 \mathrm{mmHg}$ and DBP more than $110 \mathrm{mmHg}$. The infusion was also ended when the subject suffered intolerable side effects.

\section{Measurements}

\section{Brachial blood pressure and heart rate}

Semi-recumbent brachial SBP and DBP and heart rate (HR) were recorded at the right upper arm opposite to the arm with the intravenous infusion line with a validated semi-automated oscillometric device (OMRON 705IT, OMRON Healthcare, Hoofddorp, The Netherlands).[16] Mean arterial pressure (MAP) was calculated by adding $40 \%$ of the pulse pressure (PP) to the measured DBP.[17]

\section{Cardiac Output}

Cardiac output (CO) was measured using echocardiography (AU5, Esaote, Genoa, Italy). Measurements were performed in the left lateral position. Aortic diameter (D) was measured at least three times using pulsed ultrasound at $2.5 \mathrm{MHz}$ from a standard two-dimensional long-axis parasternal view at the site of the aortic annulus; the median of these readings was 
used in the subsequent calculations. Aortic blood velocity profiles (at least 5 beats) were measured across the aortic valve with continuous ultrasound using an apical window. Stroke volume (SV) was calculated from aortic cross-sectional area $\left(\mathrm{CSA}_{\mathrm{ao}}\right)$ multiplied by the flow velocity integral (FVI).

$$
\begin{aligned}
& \mathrm{CSA}_{\mathrm{ao}} \text { was calculated as } \pi \mathrm{D}^{2} / 4 \\
& \mathrm{SV}=\mathrm{FVI} \times \mathrm{CSA}_{\mathrm{ao}} \\
& \mathrm{CO}=\mathrm{SV} \times \mathrm{HR} \text { (heart rate). }
\end{aligned}
$$

HR, as determined from the duration of the cardiac cycle on the FVI.[18] In our hands, reproducibility of aortic diameter and the FVI expressed as coefficient of variation was $4 \%$ and $6 \%$ respectively.

To relate the heart function to body size, $\mathrm{CO}$ and $\mathrm{SV}$ were divided by the body surface area (BSA) which was calculated by the Dubois \& Dubois formula[19] to get the cardiac index (CI) and the stroke index (SI).

\section{Microcirculation}

The effects on the microcirculation were estimated using total peripheral resistance index (TPRI) which was calculated as MAP divided by the CI.

\section{Macro-circulation}

Large artery wall properties were assessed for the aorta using carotid-femoral pulse wave velocity (PWV), and local distensibility and compliance were measured at the right common carotid artery (CCA) and right common femoral artery (CFA).

PWV was measured using a Sphygmocor ${ }^{\circledR}$ (AtCor Medical, Sydney, Australia) system. [20;21] Surface distance between the two recording sites was measured in supine position using an anthropometer and the supra-sternal notch (SSN) as reference point: the distance CCA-to-SSN was subtracted from the distance SSN-to-CFA. 
Arterial cross-sectional compliance (CC), a measure of buffering capacity and distensibility coefficient (DC), a measure of elasticity, were calculated as follows:[22]

$C C=\frac{\Delta A}{\Delta P}=\frac{\Pi\left(D_{s}^{2}-D_{d}^{2}\right)}{4 \Delta P}$

$D C=\frac{\Delta A / A_{d}}{\Delta P}=\frac{\left(D_{s}^{2}-D_{d}^{2}\right)}{D_{d}^{2} \Delta P}$

Where $\Delta \mathrm{A}$ is the systolic-diastolic change in arterial cross-section at a given location; $\Delta \mathrm{P}$ is the local pulse pressure (PP) at a given location; $D_{s}$ is the arterial diameter at end-systole; $D_{d}$ is the arterial diameter at end-diastole; $A_{d}$ is the arterial cross-section at end-diastole.

Arterial diameter distension waveforms were assessed with a wall-tracking vascular echoscanner (Wall Track System, Esaote, Genoa, Italy) [23] equipped with a 7.5-10 MHz linear-array. Wall motion was tracked at the interface between media and adventitia at both (near and far) walls, at 1-2 $\mathrm{cm}$ proximal to the bifurcation of the CCA and the CFA. Per location, the median of tree recordings, each lasting for 5-6 seconds, was used for data analysis. In our hands, reproducibility of diameter and displacement expressed as coefficient of variation was $4 \%$ and $6 \%$ for the CCA and 3\% and $7 \%$ for CFA, respectively. Femoral and carotid pressure waveforms (PWFs) were recorded non-invasively with a Sphygmocor ${ }^{\circledR}$ (AtCor Medical, Sydney, Australia).[24] To obtain local blood pressure at the CCA and CFA, calibration of the recorded PWFs was required. Calibration is based on the validated assumption that DBP and MAP remain constant throughout the large arteries, while SBP and PP (the difference between SBP and DBP) change.[25]

Additionally, isobaric wall properties (expressed as $\mathrm{DC}_{\mathrm{ISO}}$ and $\mathrm{CC}_{\mathrm{ISO}}$ ) were calculated for each subject. The diameter and pressure waveforms were time-aligned using the peak as reference point. The resulting diameter-time recordings at CCA and CFA were analysed off-line using Matlab®. In each 
subject, CC and DC were calculated over the blood pressure interval common in each treatment period (the highest DBP and the lowest SBP). In this way, the direct drug-induced changes in distensibility and compliance could be differentiated from the changes resulting from a change in blood pressure.

Data analysis

The median of 3 measurements was used for data-analysis. Statistics were done using IBM® SPSS ${ }^{\circledR}$ version 18 (SPSS Inc., Chicago, United States). Demographic differences between study groups were analysed using the non-parametric Mann-Whitney U test.

The cardiovascular effects were analysed by the non-parametric Kruskal-Wallis test. If statistically different ( $\mathrm{p}<0.1$ ), a Mann-Whitney $\mathrm{U}$ test was run for 2-point comparison.

\section{Results}

\section{Demographic data}

At study entry, the subgroup of 8 subjects receiving also ritodrine did not differ statistically from the whole group $(n=20)$ (Table 1). All subjects received the total amount of the planned dose, which was $300 \mu \mathrm{g} / \mathrm{min}$ for atosiban and $400 \mu \mathrm{g} / \mathrm{min}$ as the highest dose for ritodrine. Most of the adverse drug events were seen during ritodrine exposure, no adverse events happened during placebo or atosiban infusion (Table 2).

\section{Hemodynamic data}

The effects of the tocolytic drugs compared to placebo on cardiac function, blood pressure, micro- and macrocirculation are shown in Table 3.

CI with ritodrine increased significantly versus placebo (79\%). This was due to an increase in heart rate $(91 \%)$ while stroke index did not change. Administration of atosiban did not change cardiac index, stroke index or heart rate versus placebo, neither did it change blood pressure and total peripheral resistance index. In contrast ritodrine increased systolic blood pressure and heart rate, 
decreased diastolic blood pressure while mean arterial pressure did not change statistically. Ritodrine also decreased total peripheral resistance with $48 \%$.

The diameters of the CCA and the CFA were not influenced by either treatment. Ritodrine had significantly increased DC and CC of the CCA (62\% and 83\%, resp.) and of the more muscular CFA (59\% and 33\%, resp.). Since changes in blood pressure can passively change arterial wall properties, direct tocolytic drug effects were assessed at isobaric conditions. Except for $\mathrm{DC}_{\mathrm{ISO}}$ of the CFA, which tended to increase (55\%), all isobaric parameters remained significantly increased with ritodrine $\left(\mathrm{DC}_{\mathrm{ISO}}\right.$ and $\mathrm{CC}_{\mathrm{ISO}}$ of the CCA $61 \%$ and $83 \%$, respectively, and $\mathrm{CC}_{\mathrm{ISO}}$ of the CFA $28 \%$ ). Atosiban had no significant effects on the arterial wall properties of the CCA and CFA. The PWV was not influenced by ritodrine or atosiban but was positively correlated by MAP during ritodrine-infusion. Re-analysis with the adjusted parameter, did not influence the outcome.

\section{Discussion}

To the best of our knowledge this is the first placebo-controlled, randomized study investigating the effects of ritodrine and atosiban on cardiac function, micro-and macro-circulation in the same study.[26-29] Ritodrine had large effects while atosiban showed no significant influences on the cardiovascular system.

Like other studies cardiac index increased with ritodrine[30;31] and remained unchanged with atosiban.[32] In the present study the increased cardiac output with ritodrine was predominantly due to a beta ${ }_{1}$ mediated increase in heart rate, while stroke index (SI) remained unchanged. The latter is not in accordance with other data where an increased stroke volume was found.[30;31] These studies refer to data in pregnant women which had already a decreased stroke volume due to the pregnant uterus.[33] The effect of ritodrine on stroke volume and stroke index was the net result of different effects: 1) The direct betareceptor mediated increased cardiac contractility 2) and the decrease in afterload by the decrease in TPRI would increase SI, while 3) venous dilatation[30] had the opposite effect on SI by a decrease in cardiac filling and cardiac contractility. The decrease in TPRI (almost 50\%) with ritodrine 
is in line with other data[30;31] and is due to beta ${ }_{2}$ mediated vasodilation with ritodrine. The "flushing" in some subjects with ritodrine was reflecting this vasodilatation.

Ritodrine had effects on both the arterial wall properties of the CCA as the CFA. These effects were also present under isobaric conditions, indicating a direct (acute) effect of ritodrine on the arterial walls of the CCA and CFA. This effect is at least in part due to smooth muscle relaxation in the arterial wall and is in line with the in vitro observation on the umbilical artery by Dennedy et al..[34] The large effect on the less muscular CCA is somewhat surprising and is correlated with the strong vasodilation, although an ancillary acute mechanism cannot fully be excluded.In contrast, stiffness of the more elastic aorta, measured by pulse wave velocity, did not change with ritodrine. However, a small direct effect hidden by the indirect effects of changes in blood pressure and heart rate could not be expelled.[35] We tested this hypothesis by correlating PWV with its two main confounders MAP and HR. Only the MAP was positively correlated with PWV but did not change the outcome after correction for it (from $6.08 \mathrm{~m} / \mathrm{sec}$ to $6.07 \mathrm{~m} / \mathrm{sec}$ ).

\section{Clinical implications and study limitations}

The present study was carried out in non pregnant women. It is not clear whether the present results in non pregnant women can be fully extrapolated to pregnant women. Physiologic changes during pregnancy like an increase in cardiac output, a decrease in peripheral resistance[33;36] and modulation of oxytocin receptors during pregnancy[37;38] may alter the magnitude of the pharmacodynamic effects. On the other hand, pain and stress during premature labour may also confound the effects of tocolytic drugs. To elucidate these issues, this study would ideally be performed in late pregnant women without signs of premature labour. But this may be difficult because of ethical issues.

Some data-analyses were hampered by the small study population on ritodrine. However, the observed cardiovascular effects observed with ritodrine were large so that the main outcomes are not likely to be influenced by this small sample size.

Ritodrine has important effects on the cardiovascular system. Since heart rate and CI are almost doubled in comparison with placebo, it may not be the preferred drug in patients at risk of cardiac 
disorders, as the cardiovascular effects of beta-agonists could exacerbate underlying cardiovascular disease.[30;31] Also very divergent effects of ritodrine have been published like the effects on SBP starting from systolic hypotension and ending with an increased SBP like in the present study.[31;39;40]

Potential beneficial effects of ritodrine may be the higher arterial elasticity and buffering capacity and the lower peripheral resistance. These effects are largely due to a beta ${ }_{2}$-adrenergic mediated increase in endothelial nitric oxide release[41], which may alleviate the peripheral vasoconstriction due to endothelial dysfunction in cases of gestational hypertension or other vascular complications during pregnancy. However, a potential beneficial effect of ritrodrine may not be overestimated as this drug is only given for a short period of time and as the improved beta-adrenergic mediated endothelial NO release may not be present in subjects with an impaired NO pathway.[41] The latter might be the case in pregnancy since stimulated nitric oxide release was reduced in normal pregnancy and preeclampsia, while vascular smooth muscle sensitivity to nitric oxide was not altered.[42] Moreover, in hypertensive pregnancies, the circulating components of the RAAS (Renin-Angiotensin-Aldosteron system) are decreased and since beta-agonists increase the outflow of the RAAS[31;43;44], this could aggravate endothelial dysfunction and due to lowering the diastolic blood pressure, ritodrine may compromise the flow towards the placenta.[45;46] In addition, the potential beneficial vascular effects of ritodrine appear to be counterbalanced by its cardiac effects, which impels caution for the use of ritodrine in cardiovascular complicated pregnancies.

Atosiban, on the other hand, was shown to have no significant cardiovascular effects which is in agreement with previous findings. Our data add substantial information by using more complex cardiovascular measurements. However, the high cost of atosiban and the similar tocolytic effectiveness compared to ritodrine [5;47], makes it not a cost-effective alternative for widespread use.

In conclusion, the present study shows potentially beneficial vascular effects of ritodrine. These effects appear to be counterbalanced by the cardiac effects. There are no clinically relevant effects of atosiban 
on the cardiovascular system. Since the tocolytic effectiveness is the same, atosiban may be a good alternative for ritodrine in pregnant women with cardiovascular complications.

\section{Acknowledgements}

The authors would like to thank all included subjects, Mr Dries Mahieu, Mrs Tine De Backer, Mrs Fabienne De Boeck, Mrs Griet Van Lancker, Mrs Charline Wehlou, Mr Marc Twagirumukiza for the blinded medication preparation, the staff of the Drug Research Unit Ghent for their excellent technical support and Mr Sebastian Vermeersch for his know-how.

\section{Trial Number}

EudractNr: 2008-000845-76 
Table 1: Subjects' characteristics at study entry

\begin{tabular}{|c|c|c|c|}
\hline Parameters & Characteristics & & \\
\hline & Double-blinded study part $(\mathrm{n}=20)$ & Single-blinded study part $(\mathrm{n}=8)$ & p-value* \\
\hline Age (years) & $25 \pm 7$ & $25 \pm 11$ & 0.862 \\
\hline BMI $\left(\mathrm{kg} \cdot \mathrm{m}^{-2}\right)$ & $21 \pm 3$ & $22 \pm 4$ & 0.980 \\
\hline Height (m) & $1.69 \pm 0.07$ & $1.68 \pm 0.06$ & 0.901 \\
\hline Smoking n (\%) & $4(20)$ & $1(12.5)$ & 0.784 \\
\hline SBP (mmHg) & $101 \pm 7$ & $101 \pm 9$ & 0.826 \\
\hline DBP (mmHg) & $65 \pm 5$ & $67 \pm 6$ & 0.748 \\
\hline HR (bpm) & $58 \pm 8$ & $58 \pm 9$ & 0.901 \\
\hline
\end{tabular}

Twenty non-pregnant, healthy female volunteers received atosiban and placebo in a double-blinded way whereas eight of them also received ritodrine in a single-blinded way. All data are expressed as mean \pm standard deviation, except for smoking history. BMI (Body Mass Index); SBP (systolic blood pressure); DBP (diastolic blood pressure); HR (heart rate); bpm (beats per minute) 
Table 2: Adverse events during drug exposure.

\begin{tabular}{lccc}
\hline Adverse event & Ritodrine & Atosiban & Placebo \\
& $(\mathbf{n}=\mathbf{8})$ & $(\mathbf{n}=\mathbf{2 0})$ & $(\mathbf{n}=\mathbf{2 0})$ \\
\hline None & 2 & 20 & 0 \\
Tremor & 3 & 0 & 0 \\
Palpitations & 6 & 0 & 0 \\
Flushing & 2 & 0 & 0 \\
& & & 0 \\
\hline
\end{tabular}


Table 3: Cardiovascular effects of ritodrine and atosiban in healthy non-pregnant women.

\begin{tabular}{|c|c|c|c|c|}
\hline Parameters & Ritodrine $(n=8)$ & Atosiban $(n=20)$ & Placebo $(n=20)$ & p-value $e^{S}$ \\
\hline CI $\left(1 . m^{-1} \cdot m^{-2}\right)$ & $3.15 \pm 0.92^{* \#}$ & $1.85 \pm 0.58$ & $1.76 \pm 0.47$ & 0.001 \\
\hline $\mathrm{SI}\left(\mathrm{mL} \cdot \mathrm{m}^{-2}\right)$ & $28 \pm 6$ & $31 \pm 6$ & $30 \pm 7$ & 0.802 \\
\hline HR (bpm) & $111 \pm 20^{* \#}$ & $59 \pm 10$ & $58 \pm 10$ & $<0.001$ \\
\hline TPRI $\left(\mathrm{kPa} \cdot \mathrm{I}^{-1} \cdot \mathrm{min}^{-1} \cdot \mathrm{m}^{-2}\right)$ & $1.63 \pm 0.58^{* \#}$ & $3.03 \pm 1.01$ & $3.12 \pm 0.84$ & $<0.001$ \\
\hline CCA diameter (mm) & $6.52 \pm 0.93$ & $6.25 \pm 0.63$ & $6.23 \pm 0.66$ & 0.400 \\
\hline $\mathrm{DC}_{\mathrm{CCA}}\left(10^{-3} \mathrm{kPa}^{-1}\right)$ & $76.67 \pm 25.40^{* \#}$ & $53.01 \pm 20.46$ & $47.26 \pm 13.46$ & 0.006 \\
\hline $\mathrm{DC}_{\mathrm{CCA} \_\mathrm{ISO}}\left(10^{-3} \mathrm{kPa}^{-1}\right)$ & $72.49 \pm 25.17^{* \#}$ & $52.39 \pm 20.55$ & $44.98 \pm 12.40$ & 0.007 \\
\hline $\mathrm{CC}_{\mathrm{CCA}}\left(\mathrm{mm}^{2} \cdot \mathrm{kPa}^{-1}\right)$ & $2.55 \pm 0.90^{* \#}$ & $1.58 \pm 0.49$ & $1.39 \pm 0.35$ & 0.003 \\
\hline $\mathrm{CC}_{\text {CCA_ISO }}\left(\mathrm{mm}^{2} \cdot \mathrm{kPa}^{-1}\right)$ & $2.45 \pm 0.91^{* \#}$ & $1.56 \pm 0.48$ & $1.34 \pm 0.34$ & 0.003 \\
\hline CFA diameter (mm) & $7.77 \pm 1.13$ & $8.18 \pm 1.07$ & $8.27 \pm 0.81$ & 0.615 \\
\hline $\mathrm{DC}_{\mathrm{CFA}}\left(10^{-3} \mathrm{kPa}^{-1}\right)$ & $32.47 \pm 16.16^{\text {*\# }}$ & $19.40 \pm 9.19$ & $20.43 \pm 9.30$ & 0.057 \\
\hline $\mathrm{DC}_{\mathrm{CFA} \_\mathrm{ISO}}\left(10^{-3} \mathrm{kPa}^{-1}\right)$ & $30.69 \pm 15.09$ & $19.17 \pm 9.22$ & $19.83 \pm 9.12$ & 0.112 \\
\hline $\mathrm{CC}_{\mathrm{CFA}}\left(\mathrm{mm}^{2} \cdot \mathrm{kPa}^{-1}\right)$ & $1.45 \pm 0.53^{* \#}$ & $0.94 \pm 0.37$ & $1.09 \pm 0.56$ & 0.057 \\
\hline $\mathrm{CC}_{\mathrm{CFA} \_\mathrm{ISO}}\left(\mathrm{mm}^{2} \cdot \mathrm{kPa}^{-1}\right)$ & $1.36 \pm 0.50^{* \#}$ & $0.93 \pm 0.37$ & $1.06 \pm 0.55$ & 0.075 \\
\hline $\mathrm{PWV}\left(\mathrm{m} \cdot \mathrm{s}^{-1}\right)$ & $6.08 \pm 0.84$ & $5.82 \pm 0.78$ & $5.96 \pm 0.95$ & 0.730 \\
\hline SBP (mmHg) & $116 \pm 12^{* \#}$ & $105 \pm 8$ & $104 \pm 6$ & 0.067 \\
\hline DBP (mmHg) & $55 \pm 11^{* \#}$ & $69 \pm 6$ & $68 \pm 5$ & 0.004 \\
\hline MAP (mmHg) & $78 \pm 10$ & $87 \pm 9$ & $85 \pm 5$ & 0.226 \\
\hline
\end{tabular}

CI (cardiac index), SI (stroke index), HR (heart rate), TPRI (total peripheral resistance index), CCA (common carotid artery), CFA (common femoral artery), $\mathrm{DC}_{\mathrm{CCA}}$ (distensibility coefficient of the CCA); $\mathrm{DC}_{\mathrm{CCA}_{-} \text {ISo }}$ 
(isobaric $\mathrm{DC}$ of the $\mathrm{CCA}$ ); $\mathrm{CC}_{\mathrm{CCA}}$ (compliance coefficient of the $\mathrm{CCA}$ ); $\mathrm{CC}_{\mathrm{CCA} \_ \text {ISO }}$ (isobaric $\mathrm{CC}$ of the $\mathrm{CCA}$ ); $\mathrm{DC}_{\mathrm{CFA}}$ (distensibility coefficient of the $\mathrm{CFA}$ ); $\mathrm{DC}_{\mathrm{CFA} \_ \text {Iso }}$ (isobaric $\mathrm{DC}$ of the $\mathrm{CFA}$ ); $\mathrm{CC}_{\mathrm{CFA}}$ (compliance coefficient of the CFA); $\mathrm{CC}_{\mathrm{CFA}_{-} \text {ISO }}$ (isobaric $\mathrm{CC}$ of the CFA), SBP (systolic blood pressure), DBP (diastolic BP), MAP (mean arterial pressure), PWV (pulse wave velocity); ${ }^{\$}$ Kruskal-Wallis test on all subjects, comparing three groups : ${ }^{*}$ significant versus atosiban; ${ }^{\#}$ significant versus placebo. All data are shown as mean \pm standard deviation. 


\section{Reference List}

1. de Heus R, Mol BW, Erwich JJ, van Geijn HP, Gyselaers WJ, Hanssens M, Harmark L, van Holsbeke CD, Duvekot JJ, Schobben FF, Wolf H, Visser GH. Adverse drug reactions to tocolytic treatment for preterm labour: prospective cohort study. BMJ 2009; 338: b744.

2. Kwong MS, Egan EA. Reduced incidence of hyaline membrane disease in extremely premature infants following delay of delivery in mother with preterm labor: use of ritodrine and betamethasone. Pediatrics 1986; 78: 767-774.

3. Caughey AB, Parer JT. Tocolysis with beta-adrenergic receptor agonists. Semin.Perinatol. 2001; 25: 248-255.

4. Shim JY, Park YW, Yoon BH, Cho YK, Yang JH, Lee Y, Kim A. Multicentre, parallel group, randomised, single-blind study of the safety and efficacy of atosiban versus ritodrine in the treatment of acute preterm labour in Korean women. BJOG. 2006; 113: 1228-1234.

5. Shubert PJ. Atosiban. Clin.Obstet.Gynecol. 1995; 38: 722-724.

6. Chan J, Cabrol D, Ingemarsson I, Marsal K, Moutquin JM, Fisk NM. Pragmatic comparison of beta2-agonist side effects within the Worldwide Atosiban versus Beta Agonists study. Eur.J.Obstet.Gynecol.Reprod.Biol. 2006; 128: 135-141.

7. Stergiotou I, Talbot F, Yoong W. The use of atosiban and ritodrine in external cephalic version. Acta Obstet.Gynecol.Scand. 2007; 86: 927-929.

8. Ferriols LR, Nicolas PJ, Alos AM. [Pharmacoeconomic assessment of two tocolysis protocols for the inhibition of premature delivery]. Farm.Hosp. 2005; 29: 18-25.

9. Effectiveness and safety of the oxytocin antagonist atosiban versus beta-adrenergic agonists in the treatment of preterm labour. The Worldwide Atosiban versus Beta-agonists Study

Group. BJOG. 2001; 108: 133-142.

10. Fabry I, De PP, Kips J, Vermeersch S, Van BL. Different effects of tocolytic medication on blood pressure and blood pressure amplification. Eur.J.Clin.Pharmacol. 2011; 67: 11-17.

11. Van Bortel LM, Duprez D, Starmans-Kool MJ, Safar ME, Giannattasio C, Cockcroft J, Kaiser DR, Thuillez C. Clinical applications of arterial stiffness, Task Force III: recommendations for user procedures. Am.J.Hypertens. 2002; 15: 445-452.

12. Gerris J, Thiery M, Bogaert M, De SA. Randomized trial of two beta-mimetic drugs (ritodrine and fenoterol) in acute intra-partum tocolysis. Eur.J.Clin.Pharmacol. 1980; 18: 443-448.

13. Papatsonis DN, van Geijn HP, Ader HJ, Lange FM, Bleker OP, Dekker GA. Nifedipine and ritodrine in the management of preterm labor: a randomized multicenter trial. Obstet.Gynecol. 1997; 90: 230-234.

14. Rasmussen BB, Larsen LS, Senderovitz T. Pharmacokinetic interaction studies of atosiban with labetalol or betamethasone in healthy female volunteers. BJOG. 2005; 112: 1492-1499. 
15. Tsatsaris V, Carbonne B, Papatsonis D, Goffinet F. Nifedipine versus ritodrine for suppression of preterm labor; a meta-analysis. Acta Obstet.Gynecol.Scand. 2000; 79: 618-619.

16. Vanmolkot FH, Van Bortel LM, de Hoon JN. Altered arterial function in migraine of recent onset. Neurology 2007; 68: 1563-1570.

17. Bos WJ, Verrij E, Vincent HH, Westerhof BE, Parati G, van Montfrans GA. How to assess mean blood pressure properly at the brachial artery level. J.Hypertens. 2007; 25: 751-755.

18. Huntsman LL, Stewart DK, Barnes SR, Franklin SB, Colocousis JS, Hessel EA. Noninvasive Doppler determination of cardiac output in man. Clinical validation. Circulation 1983; 67 : 593-602.

19. Du BD, Du Bois EF. A formula to estimate the approximate surface area if height and weight be known. Nutrition 1989; 5: 303-311.

20. Wilkinson IB, Cockcroft JR, Webb DJ. Pulse wave analysis and arterial stiffness.

J.Cardiovasc.Pharmacol. 1998; 32 Suppl 3: S33-S37.

21. Vlachopoulos C, Aznaouridis K, Stefanadis C. Prediction of cardiovascular events and all-cause mortality with arterial stiffness: a systematic review and meta-analysis. J.Am.Coll.Cardiol. 2010; 55: 1318-1327.

22. Vermeersch SJ, Rietzschel ER, De Buyzere ML, De BD, De BG, Van Bortel LM, Gillebert TC, Verdonck PR, Segers P. Age and gender related patterns in carotid-femoral PWV and carotid and femoral stiffness in a large healthy, middle-aged population. J.Hypertens. 2008; 26: 1411-1419.

23. Hoeks AP, Brands PJ, Smeets FA, Reneman RS. Assessment of the distensibility of superficial arteries. Ultrasound Med.Biol. 1990; 16: 121-128.

24. Kelly R, Hayward C, Avolio A, O'Rourke M. Noninvasive determination of age-related changes in the human arterial pulse. Circulation 1989; 80: 1652-1659.

25. Kelly R, Fitchett $D$. Noninvasive determination of aortic input impedance and external left ventricular power output: a validation and repeatability study of a new technique.

J.Am.Coll.Cardiol. 1992; 20: 952-963.

26. Goodwin TM, Millar L, North L, Abrams LS, Weglein RC, Holland ML. The pharmacokinetics of the oxytocin antagonist atosiban in pregnant women with preterm uterine contractions.

Am.J.Obstet.Gynecol. 1995; 173: 913-917.

27. Goodwin TM, Valenzuela G, Silver H, Hayashi R, Creasy GW, Lane R. Treatment of preterm labor with the oxytocin antagonist atosiban. Am.J.Perinatol. 1996; 13: 143-146.

28. Moutquin JM, Sherman D, Cohen H, Mohide PT, Hochner-Celnikier D, Fejgin M, Liston RM, Dansereau J, Mazor M, Shalev E, Boucher M, Glezerman M, Zimmer EZ, Rabinovici J. Doubleblind, randomized, controlled trial of atosiban and ritodrine in the treatment of preterm labor: a multicenter effectiveness and safety study. Am.J.Obstet.Gynecol. 2000; 182: 11911199.

29. Papatsonis DN, van Geijn HP, Bleker OP, Ader HJ, Dekker GA. Hemodynamic and metabolic effects after nifedipine and ritodrine tocolysis. Int.J.Gynaecol.Obstet. 2003; 82: 5-10. 
30. Hosenpud JD, Morton MJ, O'Grady JP. Cardiac stimulation during ritodrine hydrochloride tocolytic therapy. Obstet.Gynecol. 1983; 62: 52-58.

31. Lamont RF. The pathophysiology of pulmonary oedema with the use of beta-agonists. BJOG. 2000; 107: 439-444.

32. Tsatsaris V, Carbonne B, Cabrol D. Atosiban for preterm labour. Drugs 2004; 64: 375-382.

33. Schneider KT, Deckardt R. The implication of upright posture on pregnancy. J.Perinat.Med. 1991; 19: 121-131.

34. Dennedy MC, Houlihan DD, McMillan H, Morrison JJ. Beta2- and beta3-adrenoreceptor agonists: human myometrial selectivity and effects on umbilical artery tone.

Am.J.Obstet.Gynecol. 2002; 187: 641-647.

35. Lantelme P, Mestre C, Lievre M, Gressard A, Milon H. Heart rate: an important confounder of pulse wave velocity assessment. Hypertension 2002; 39: 1083-1087.

36. Duvekot JJ, Peeters LL. Maternal cardiovascular hemodynamic adaptation to pregnancy. Obstet.Gynecol.Surv. 1994; 49: S1-14.

37. Gimpl G, Fahrenholz F. The oxytocin receptor system: structure, function, and regulation. Physiol Rev. 2001; 81: 629-683.

38. Mitchell BF, Schmid B. Oxytocin and its receptor in the process of parturition. J.Soc.Gynecol.Investig. 2001; 8: 122-133.

39. Cekici L, Valipour A, Kohansal R, Burghuber OC. Short-term effects of inhaled salbutamol on autonomic cardiovascular control in healthy subjects: a placebo-controlled study. Br.J.Clin.Pharmacol. 2009; 67: 394-402.

40. Waring WS, Sinclair HM, Webb DJ. Effects of salbutamol and glyceryl trinitrate on large arterial stiffness are similar between patients with hypertension and adults with normal blood pressure. Br.J.Clin.Pharmacol. 2006; 62: 621-626.

41. Dawes M, Chowienczyk PJ, Ritter JM. Effects of inhibition of the L-arginine/nitric oxide pathway on vasodilation caused by beta-adrenergic agonists in human forearm. Circulation 1997; 95: 2293-2297.

42. Anumba DO, Ford GA, Boys RJ, Robson SC. Stimulated nitric oxide release and nitric oxide sensitivity in forearm arterial vasculature during normotensive and preeclamptic pregnancy. Am.J.Obstet.Gynecol. 1999; 181: 1479-1484.

43. Vesalainen RK, Ekholm EM, Jartti TT, Tahvanainen KU, Kaila TJ, Erkkola RU. Effects of tocolytic treatment with ritodrine on cardiovascular autonomic regulation. Br.J.Obstet.Gynaecol. 1999; 106: 238-243.

44. Bussen SS, Sutterlin MW, Steck T. Plasma renin activity and aldosterone serum concentration are decreased in severe preeclampsia but not in the HELLP-syndrome. Acta Obstet.Gynecol.Scand. 1998; 77: 609-613. 
45. Noori M, Donald AE, Angelakopoulou A, Hingorani AD, Williams DJ. Prospective study of placental angiogenic factors and maternal vascular function before and after preeclampsia and gestational hypertension. Circulation 2010; 122: 478-487.

46. Simmons LA, Hennessy A, Gillin AG, Jeremy RW. Uteroplacental blood flow and placental vascular endothelial growth factor in normotensive and pre-eclamptic pregnancy. BJOG. 2000; 107: 678-685.

47. Wex J, Connolly M, Rath W. Atosiban versus betamimetics in the treatment of preterm labour in Germany: an economic evaluation. BMC.Pregnancy.Childbirth. 2009; 9: 23. 